\title{
A Damage Function for Stem Rust of Perennial Ryegrass Seed Crops
}

\author{
W. Pfender
}

U.S. Department of Agriculture-Agricultural Research Service, National Forage Seed Production Research Center/Oregon State University Department of Botany and Plant Pathology, 3450 SW Campus Way, Corvallis 97331.

Accepted for publication 9 January 2009.

\section{ABSTRACT}

Pfender, W. 2009. A damage function for stem rust of perennial ryegrass seed crops. Phytopathology 99:498-505.

Observations of naturally occurring stem rust epidemics and seed yields in perennial ryegrass were taken in 19 field experiments conducted over the course of 9 years. Epidemic severity differed among years and also among experimental treatments (fungicide regimes) within years. In each experiment, attainable yield was represented by the nondiseased treatment, and yields of other treatments were expressed as relative yield (a proportion of the attainable yield). Yield loss (difference between attainable and actual yield) in the nonprotected treatments was 0 to $98 \%$ due to yearly differences in epidemic conditions. Fungicides were effective in reducing stem rust injury and damage when properly timed. Disease severity in the upper canopy was estimated at approximately weekly intervals and converted to proportion of the plant area diseased. The complementary value, proportion of area healthy, and its integral over time, healthy area duration (HAD), were calculated. Regression analyses were conducted using various phenological time intervals of HAD as the independent variable. The best intervals of HAD for predicting relative yield were centered on the midpoint time between anthesis and harvest. The regression equation $\left(r^{2}=0.89\right)$ for relative yield as a function of HAD during the 3 -week interval was selected and rearranged to produce a quadratic damage function. This damage function estimates yield loss at 5, 22, and $42 \%$ for critical-interval diseased proportions of 1,5 , and $10 \%$, respectively. Yield data collected from field experiments not used in model development correlated well $\left(r^{2}=0.9\right)$ with yields predicted by the damage function from their observed disease severity.

Additional keywords: azoxystrobin, Lolium perenne, propiconazole, Puccinia graminis subsp. graminicola.
Knowledge of the relationship between injury (observable symptoms of disease) and damage (reduction in yield quantity or quality) (14) for a plant disease is valuable in several respects (19). Such information provides an economic foundation for setting priorities for research and allocation of crop protection resources. In addition, tactical control decisions (i.e., those made during crop growth) must be based on an accurate damage/injury relationship to maximize benefit per cost $(11,15,19)$. Without such information, over- or underprotection based on incorrect assumptions of the economic consequences of disease can lead to economic losses through excessive costs or unnecessary yield shortfalls (19). The goal is to balance management costs against the gains obtained by reducing the gap between the crop's "attainable yield" for a given physical environment and the "actual yield" realized through management in that environment (14).

The extent of damage due to disease is best considered to be related to physiological effects on host rather than to severity of the disease directly $(6,15)$. For a grass or grain crop, disease may affect yield through reduction in yield potential (i.e., number of fertile florets that can produce seed) or yield realization (i.e., seed filling) (6). Although the effects of plant diseases on productivity can be physiologically complex, most diseases can be thought of as interfering with photosynthetic activity, either by reducing interception of radiation or by decreasing the efficiency with which the intercepted radiation is used $(6,12)$. If a disease causes radiation use efficiency to be decreased systemically within the plant,

Corresponding author: W. Pfender; E-mail address: pfenderw@onid.orst.edu

\section{doi:10.1094/PHYTO-99-5-0498}

This article is in the public domain and not copyrightable. It may be freely reprinted with customary crediting of the source. The American Phytopathological Society, 2009 small increments of disease severity can result in relatively large increments of damage. Alternatively, if a disease acts primarily to reduce the area of photosynthetically competent host tissue (whether through senescence or overt destruction) and the crop has leaf area in surplus of that needed for maximum yield, the crop can sustain a larger increment of damage with relatively smaller effects. In the latter case, the curve fit to yield per healthy crop area will be monotonically increasing but will be concave downward $(8,13)$, with the degree of concavity reflecting the ability of the canopy to compensate for lost area. It appears that most plant diseases are of the latter type (6). For these diseases, one would expect the difference between attainable and actual yields for a given crop to be a function of healthy photosynthetic area integrated over the time duration of critically important phenological stages $(6,21)$. The form of this function is affected by canopy architecture with respect to light interception and disease location $(6,17)$. Bancal et al. (1) found that correlations of wheat yield with photosynthetic area were greatly improved by accounting for each leaf layer of the canopy with respect to healthy area and light interception. Light falling on a crop canopy is mostly absorbed by the first leaves it reaches, and its penetration into the canopy is characterized by an exponential extinction (Beer's law). The equation describing this relationship typically uses leaf area index (LAI) (area of plant surfaces per unit ground area) as the independent variable, with an extinction coefficient characteristic for a given crop. In forage grasses, the extinction coefficient is relatively high due to the horizontal habit of the upper leaves, and typically $80 \%$ of photosynthetically active radiation is absorbed by canopies with LAI of $4(3,20)$. Measurements in a ryegrass canopy indicate that a LAI of 3 can occur in the top $15 \mathrm{~cm}$ of a $25-\mathrm{cm}$ tall canopy or in the top $5 \mathrm{~cm}$ of a $35-\mathrm{cm}$ tall canopy (5). As grass leaves flag (i.e., become more horizontal with plant growth), an increasingly higher proportion of incident light is absorbed by the upper portion of the canopy. 
Therefore, the damage/injury relationship should be dominated by the upper portion of the grass canopy and disease that reduces photosynthetic area there.

In cool-season grasses grown for seed, the economically most important disease in major production areas of the United States and New Zealand is stem rust caused by Puccinia graminis subsp. graminicola. Perennial ryegrass seed yield shortfalls of $35 \%$ due to stem rust injury have been reported from New Zealand (7). In the United States, experimental plots of perennial ryegrass with stem rust yielded only $80 \%$ as much as plots in which the disease was controlled (22). In experiments conducted on single plants as the experimental unit, $90 \%$ yield differences between protected and unprotected plants were observed (22). Hampton (7) found yield shortfalls to be caused mostly by reduced number of seed but also by reduced seed filling (lower seed weights). These reports show disease severities at harvest (22) or at anthesis and harvest (7) but do not provide data on disease severities or healthy canopy area integrated through the growing season.

Decision support tools for crop disease management are warranted if the disease produces economically significant yield shortfalls, if it occurs commonly but not invariably, and if there are economically viable management procedures available (4). Grass seed growers in the northwestern United States together spend millions of dollars annually for fungicides to manage stem rust. One purpose of the research reported here is to document the range and year-to-year variability of damage to the perennial ryegrass seed crop due to stem rust. A larger goal is to produce a damage function for this pathosystem. A damage function, including specification of the phenological crop stages that are most correlated with damage, will be applicable in designing and implementing a decision support tool for stem rust in grass seed crops.

\section{MATERIALS AND METHODS}

Field experiment design. A series of 19 experiments was conducted over the course of 9 years to develop data sets of stem rust severity and seed yield across a range of epidemic patterns (Table 1). The experiments were done at Hyslop Experiment Farm north of Corvallis, OR. Each experiment consisted of two or more replicated, randomized treatments with respect to fungicide application, including one treatment maintained as disease-free to provide a measure of attainable yield. In most years, two or more different experiments were conducted, usually differing in fall planting date because this factor can affect epidemic severity (16). Seed crops of perennial ryegrass typically are planted in the autumn, the first harvest is taken in July, and the stand is maintained and harvested annually for several additional years. In our experiments, we collected data from first-year stands as well as from second-year stands.

Plots were established by planting seed of perennial ryegrass (cv. Morningstar) at a rate of $11 \mathrm{~kg} / \mathrm{ha}$ in rows $30 \mathrm{~cm}$ apart. The standard seeding practice was used, as previously described (16), in which the seeded row is covered with a band of carbon to protect the crop seeds from a herbicide applied immediately after planting. Fertilizer applied at planting supplied $39 \mathrm{~kg}$ each of $\mathrm{N}$ and $\mathrm{P}\left(\right.$ as $\left.\mathrm{P}_{2} \mathrm{O}_{5}\right)$, and $33 \mathrm{~kg}$ of $\mathrm{S}$ per hectare. Additional $\mathrm{N}$ fertilizer (granular urea) was applied in mid-March and mid-April each year, at a rate of $\mathrm{N}$ at $67 \mathrm{~kg} / \mathrm{ha}$ for each application. Second-year stands received $\mathrm{N}, \mathrm{P}\left(\right.$ as $\mathrm{P}_{2} \mathrm{O}_{5}$ ), and $\mathrm{K}$ at $42 \mathrm{~kg} / \mathrm{ha}$ each in October (i.e., $\approx 1$ year after planting). Standard practices were followed for chemical weed control during the season, including an application to second-year stands in October for the control of volunteer crop seedlings. In some years, several experiments were planted, each with a different planting date. "Early-planted" plots in different years were seeded between 15 and 25 September, "mid-planted" plots between 15 and 20 October, and "late-planted" plots between 25 October and 5 November. In most crop seasons, there was an experiment in a second-year stand also. In 1998, when there was no second-year stand available, two experiments were done that differed in the amount of $\mathrm{N}$ fertilizer applied in spring. Experiments were set out as randomized complete blocks, with treatments differing in fungicide application (timing or fungicide type). The design of each experiment was balanced and the number of replicates per treatment in different years varied from three to five. Blocks were separated from one another by at least 6 $\mathrm{m}$ of nonplanted ground kept free of weeds, providing an alleyway for spraying and disease assessment without driving or walking in adjacent plots. Distance between replicates within a block was at least $6 \mathrm{~m}$. Each replicate plot was 4.2 by $7.5 \mathrm{~m}$ in 1998 to $2002,4.2$ by $16 \mathrm{~m}$ in 2003 to 2005 , and 2.1 by $10 \mathrm{~m}$ in 2006.

Stem rust epidemics in all years originated from naturallyoccurring inoculum, and no inoculations were made. To obtain a range of intensities of epidemic development, including a diseasefree treatment, the two commonly used fungicides in grass seed production (propiconazole and azoxystrobin) were applied in various sequences and timings. Timing of applications also was varied to produce early- or late-developing epidemics. In 1998 and 1999, azoxystrobin was not yet labeled for this crop; therefore, only propiconazole was used. In subsequent years, the two fungicides were used singly or in various combinations (Table 1). Fungicides were applied with a boom sprayer pulled by a tractor driven in the nonplanted alleyways beside the blocks of ryegrass. Propiconazole was applied at $184 \mathrm{~g}$ a.i./ha as Tilt (Syngenta, Inc., Basel, Switzerland) at $440 \mathrm{ml} / \mathrm{ha}$ in 187 liters of water per hectare at a pressure of $129 \mathrm{KPa}(150 \mathrm{KPa}$ in 2005 and 2006). Azoxystrobin was applied at $150 \mathrm{~g}$ a.i./ha as Quadris (Syngenta Inc.) at $660 \mathrm{ml} / \mathrm{ha}$, with the same volume and pressure as the propiconazole. For application of Quadris, a surfactant (polyol fatty acid and derivatives at $2.8 \mathrm{~kg}$ a.i./ha) (Agridex, Helena, MT) was added to the water. The sprayer was equipped with Teejet nozzles XR8002VS in 1998 to 2004 and AIC11002VS in 2005 and 2006. In 2005 and 2006, some of the fungicide applications were a mixture of propiconazole and azoxystrobin (Quilt at 1,460 ml/ha; propiconazole and azoxystrobin at 185 and $111 \mathrm{~g}$ a.i./ha, respectively). In most experiments, a nontreated check, in which stem rust was allowed to develop unhindered, was included also.

Disease measurement. Our objective was to measure disease severity in the part of the canopy most responsible for photosynthesis (i.e., the part that absorbs most of the incident solar radiation). Leaf area measurements taken during the season (W. Pfender, unpublished data) indicated that the LAI of a perennial ryegrass seed crop can reach a maximum of 13 to 15 a week before anthesis, then decline (due to leaf senescence) to $\approx 8$ to 10 by a week before harvest. Given this large LAI, and the pattern of light absorption described by Beer's Law, it is clear that the upper portion of this canopy, and not its full depth, is responsible for most of the absorption of incident solar radiation. From other reports $(3,5), \approx 80 \%$ of the incident light is absorbed in the top $15 \mathrm{~cm}$ of a grass canopy. Furthermore, the crop typically lodges shortly after the time of full anthesis, and the dense layer of leaves, stems, and flower heads at the top of the canopy forms a mat that absorbs most of the incident light. Therefore, we developed a disease assessment procedure that focuses on the upper portion of the canopy at any given growth stage, where most of the photosynthetically active light is absorbed (3). To sample, we tossed a sampling square (25-by-25-cm square of plexiglass with a 15 -by-15-cm square hole cut in the middle) onto the plot and determined the amount of sporulating rust pustules visible in the 15-by-15-cm opening. In April and May, when the canopy had closed but plants had not yet lodged, the opening of the sampling square was held vertically and pressed against the upper $15 \mathrm{~cm}$ of the canopy to view the sample. After the crop lodged, the sample was viewed by pressing the sampling square horizontally onto the 
TABLE 1. Fungicide treatments, final stem rust disease severity, and seed yields in experiments (Exp.) conducted from 1998 to 2006 in perennial ryegrass grown for seed ${ }^{\mathrm{a}}$

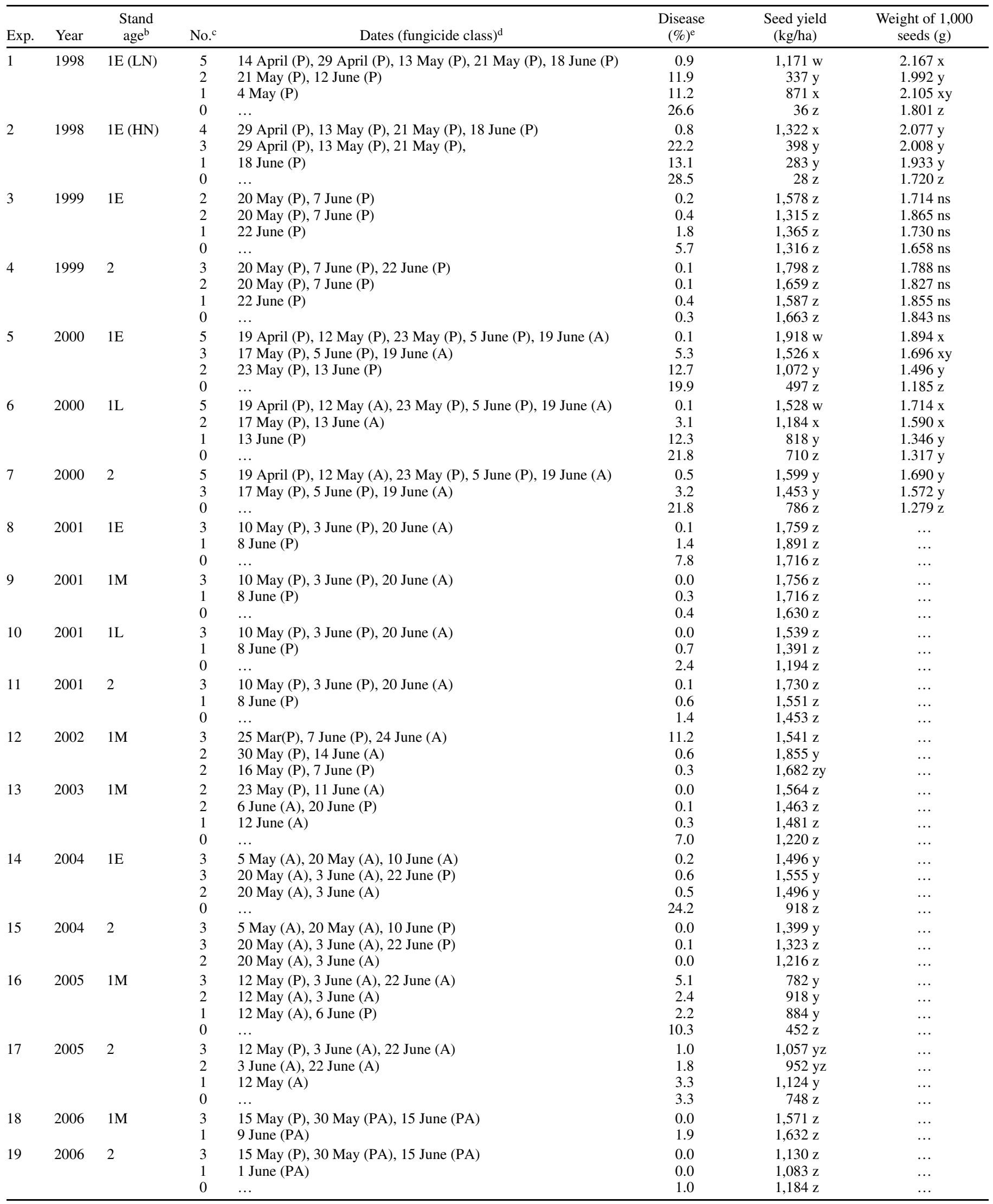

a Within a column and within an experiment, values followed by the same letter do not differ $(P=0.05)$ by Tukey's test; ns $=$ nonsignificant

${ }^{b}$ Stand age: 1 = first-year stand and $2=$ second-year stand. Within first-year stands, planting dates are indicated by $\mathrm{E}=\mathrm{early}, \mathrm{M}=\mathrm{mid}$, and $\mathrm{L}=$ late. In 1998 , two fertilizer treatments, low nitrogen $(\mathrm{LN})$ and high nitrogen $(\mathrm{HN})$, were applied.

c Number of fungicide applications.

${ }^{\mathrm{d}}$ Date and class of fungicide applications: $\mathrm{P}=$ propiconazole, $\mathrm{A}=$ azoxystrobin, and $\mathrm{PA}=$ propiconazole + azoxystrobin tank mix.

e Disease severity (percentage of plant area diseased) determined on the day of harvest. 
canopy. To reduce the disturbance caused by sampling, the plots were not entered directly. Instead, the person conducting the sampling lay on a wheeled creeper that rolled along an aluminum ladder placed horizontally across the plot, supported at a height just above the top of the canopy. The sampling square was treated with ethanol between samples to reduce spreading of inoculum. Plots were sampled for disease severity at approximately weekly intervals. When the number of pustules within a 15-by-15-cm sample window was $<50$, pustules were counted. For greater severities, the amount of disease was estimated as a percentage of sampled leaf area, by comparison with a set of photographs of 15by-15-cm samples showing a graduated series of severities, as described previously (16). Severity scores of $<50$ pustules were converted to proportion of sampled leaf area diseased by using a standard average area $\left(4.5 \mathrm{~mm}^{2}\right)$ per pustule.

Yield determination. Plots were harvested when moisture in the maturing seed had dropped to $\approx 32 \%$ (9), at dates ranging from 29 June to 12 July depending on stand age and year of the experiment. Although the equipment and methods used for swathing and threshing differed among years, a common set of procedures was used for all plots in any given year. In 1998 to 2002, a customized plot harvester was used to cut the crop (6 rows by $6 \mathrm{~m}$ ) and collect it in large burlap bags that were hung outdoors to dry. The dried crop was threshed in a stationary belt thresher. In 2003 to 2006, the crop was cut with a small plot swather ( 1.5 by $14 \mathrm{~m}$ in 2003 and 2004 and 3 by $9 \mathrm{~m}$ in 2005 and 2006), placed in windrows to dry, and threshed with a small-plot combine. In all years, a standard procedure was used to clean seed of inert material to achieve industry standards for clean seed and dried to $10 \%$ moisture content before determining weight. In 1998, 1999, and 2000, a 1,000-seed sample from each plot was weighed to determine average seed weight.

Data analysis. The approach for developing a damage function was to use the healthy area duration (HAD) (21) (i.e., the product of time $\times$ nondiseased plant area) as a predictor for yield. Both $\mathrm{HAD}$ and yield were expressed in relative terms, as proportions of the maximum possible, so that the damage function could be used across a range of cropping situations to estimate yield loss relative to maximum attainable yield.

HAD was calculated from the weekly disease severity ratings. The rust severities across all replications of a given treatment were averaged to give the treatment's mean severity for each scoring date in that particular experiment. The severities were expressed as a proportion of the total plant area in the sampling grid that was diseased. Healthy area proportion was then computed as 1.0 - (diseased proportion). This healthy area proportion was plotted against time (expressed in days). The time scale was shifted for each experiment as needed to align experiments with respect to phenological development time (i.e., time was normalized to number of days before or after key phenological events such as inflorescence emergence, anthesis, or harvest). The plotted points were connected to create a healthyarea curve (the complement of a disease progress curve). The curve was not necessarily monotonic but could decrease as the pathogen population grew or increase when fungicide action was followed by new plant growth. The proportion of healthy area for each day could then be calculated from the equations for the lines connecting the data points. Thus, the HAD for a given time interval was the area under the curve, obtained by summing the daily healthy area proportions for all the days in the interval.

The yield for each treatment was calculated as the average seed yield across all replications of the treatment in a given experiment. This average yield was then divided by the average yield obtained in the nondiseased treatment within the same experiment, producing a relative yield (0 to 1.0) for each treatment within its respective experiment. Although a yield-enhancing effect independent of disease control has been suggested for strobilurins, there are no quantitative data to support this hypothesis (2). As discussed subsequently in this article, we have taken an approach that takes fungicide-protected yield as the attainable yield.

Development of the damage function was done as an iterative process in order to get information from all experiments, including those in which a nondiseased yield was not obtainable. The first step of the process used only those experiments that did have a nondiseased yield reference (final disease severity $\leq 0.1 \%$ ). This group comprised 8 of the 19 experiments (Table 1). Relative yield of each treatment in the context of its experiment was calculated as described in the previous paragraph, and these relative yield values from all treatments across the eight experiments were combined and plotted as the dependent variable against their respective HAD values. The optimum interval for HAD as a predictor of relative yield was determined by calculating the linear regression coefficient for each of many intervals that differed in starting time (e.g., day of head emergence) and duration (number of days). The interval with the largest regression coefficient and acceptable (nonpatterned) residuals was taken as the optimum HAD predictor of relative yield. In the second step of the iterative process, this optimum predictor interval was used to estimate expected nondisease yield (i.e., maximum attainable yield) in the remaining 11 experiments. Data from each of these experiments separately were plotted as actual yield (grams/unit plot area) for each treatment as a function of the optimum HAD for the interval derived in step one. The line joining these points was extrapolated to estimate the yield that would be expected to occur at a HAD value of 1.0, and this value was taken as the nondisease yield value. In all cases, this extrapolation extended no more than 0.01 units of HAD, so the extent of extrapolation was minor. With this derived nondiseased yield value, relative yield of each remaining treatment within each experiment was calculated as previously described. The data points (relative yield and proportion of HAD) from these 11 experiments were then combined with those from the other 8 experiments. Optimization of the interval for HAD, as previously described, was then repeated for the full data set of 19 experiments. The regression equation describing relative yield as a function of proportion of HAD over this optimum interval was obtained, then rearranged algebraically to represent a damage function (yield shortfall as a function of diseased area over the critical time interval). Results using all data (19 experiments) were compared with results derived only from the eight experiments that had a nondiseased observation.

Model assessment. In addition to the experiments to collect data for development of the damage function, data were collected from unrelated field experiments to independently assess performance of the damage function. The latter experiments used perennial ryegrass cultivars different from the one used in the development-phase experiments, and some were conducted at different locations. Due to design constraints, and growers' reluctance to leave multiple large portions of fields untreated with fungicide, data for untreated crops were available for only single plots at these locations. An experiment with four cultivars (Kingston, Jet, Linn, and Manhattan 4) was planted at Hyslop Experiment Farm in 2005 for the 2006 cropping season. There was one check (no fungicide) plot and three fully treated (for nondisease reference yield) plots for each of these cultivars. Plot size and procedures were as described for the other Hyslop experiments. In 2005, 2006, and 2007, large-scale trials were conducted in grower fields at several different locations in the Willamette Valley. Cultivars in these large-scale experiments included Stellar, Paragon, OS, and VNS. Replicate plot size in these experiments was 5 by $150 \mathrm{~m}$, and commercial practices were followed in growing the crop. In each of these experiments, there was one nontreated plot and three replicate plots for each of two or three additional treatments that differed in fungicide 
application frequency. At each site, one of the treatments received fungicide applications frequently enough to produce disease-free plots for use as the nondisease yield reference. The large-scale trials were assessed for disease level approximately every 10 days and were harvested and cleaned with commercial equipment. HAD for each plot was calculated as previously described, and seed yield in each plot was divided by the average yield of the nondiseased plots for the respective cultivar and location to obtain the value for relative yield. The HAD for each replicate plot (excluding the nondisease plots) was plotted against relative yield for comparison with the modeled damage function. The data points were combined to provide a set of independent observations across a range of conditions for comparing model predictions with observations using a correlation approach. The correlation coefficient was calculated for observed relative yield versus the relative yield calculated from the damage function applied to the observed HAD.

\section{RESULTS}

Epidemic severity and fungicide effectiveness. There were marked year-to-year differences in severity of naturally occurring stem rust epidemics in perennial ryegrass (Table 1, nonfungicide treatments). Final disease severities in nontreated plots reached levels of $>20 \%$ in 3 of 9 years (1998, 2000, and 2004). The years 1999, 2001, and 2006 had very mild stem rust epidemics, and the other 3 years were intermediate in severity. In years of severe epidemics, there were statistically significant differences in seed yield among the various fungicide application treatments. In the early-planted stands in 2000, the three-application and two-application fungicide treatments yielded 80 and $56 \%$ of the fully protected (four-application) treatment; the nonprotected treatment yielded $26 \%$ of the attainable yield. In 1998, yields in the nonprotected plots were only 2 to $3 \%$ of the attainable yield. In years with mild epidemics, fungicide applications did not increase yields significantly within the context of these experiments. Yield variability is quite high in this heterogeneous forage crop; therefore, the power of statistical tests within a single year's data is somewhat limited, and several experiments in years with moderate disease levels showed no statistically significant yield differences. Seed weights (weight of 1,000 seeds) measured in the first 3 years of experiments were significantly lower in non-

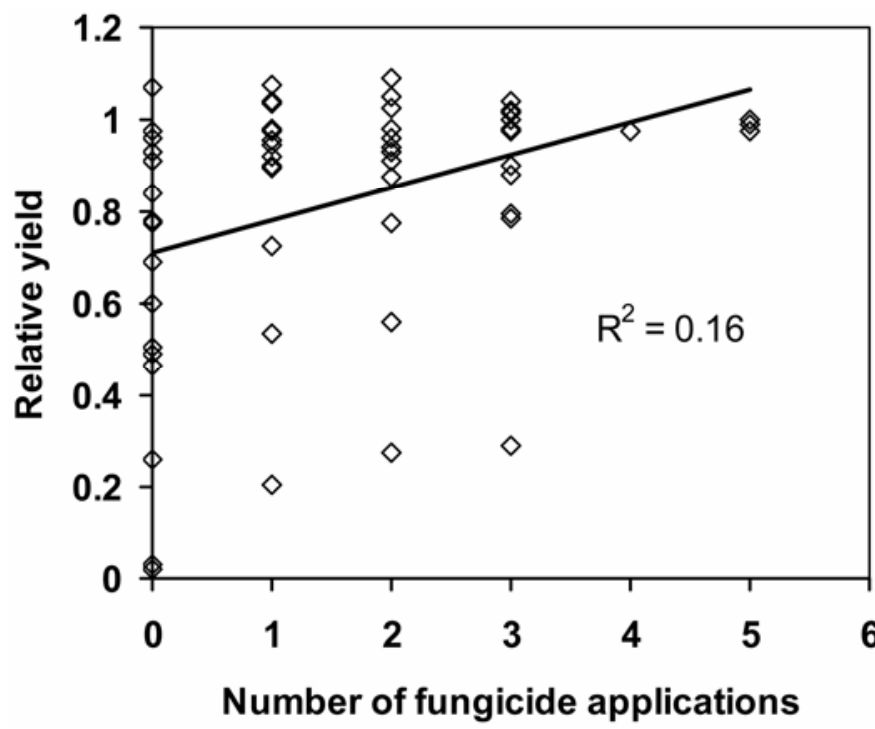

Fig. 1. Relationship of seed yield of perennial ryegrass to number of fungicide applications for stem rust in 19 field experiments conducted from 1998 to 2006. Each data point is the mean yield for one replicated treatment with the indicated number of applications during the growing season. protected treatments during severe epidemic years 1998 and 2000 (Table 1). However, the overall yield disparity among treatments could be attributed only partly to average seed weight, indicating that damage was expressed largely through flower or seed abortion that resulted in fewer seed being produced or filling adequately to remain through the seed-cleaning process that removes light (nonviable) seed.

Fungicides were effective in reducing stem rust injury and damage (Table 1). However, timing of fungicide application and severity of the epidemic appeared to exert a large influence on the outcome. Therefore, the number of fungicide applications does not necessarily correlate well with degree of yield maintenance (Fig. 1). On the one hand, if a large enough number of sprays (four or five) was used (for example, in a calendar-based program), yields were maintained even in a severe epidemic year. In other years, actual yields were very similar to attainable yields even in the absence of fungicide sprays. However, it was possible to experience severe yield limitation even with three spray applications, if they were poorly timed (Fig. 1). Thus, there were examples in which more fungicide was used than was necessary, and others in which inadequate control was achieved even with appreciable fungicide input.

Yield and HAD. Over all experiments, the average date (day of the year) for mid-anthesis was day 156 and the date of harvest was day 188. As described previously, data from all experiments were normalized to these time points. When relative yield (actual yield as proportion of attainable yield) was compared against single-day healthy area estimates, the highest correlation was for healthy area on day 171, midway between anthesis (day 156) and harvest (day 188) (Fig. 2). The shape of the curve for single-day data in Figure 2 indicates higher correlations for days after this midpoint than before it. Cumulative HAD for time intervals of 1 , 2 , or 3 weeks similarly showed highest correlation with yield for intervals centered on day 171 (Fig. 2). Correlation between healthy area and yield was low for time periods earlier than anthesis or later than 1 week before harvest. The model for relative yield as a function of HAD during the 3 weeks centered on day 171 is shown in Figure 3A. The model derived from the subset of experiments that had a nondiseased reference yield is shown as the broken line in Figure 3A. The difference between these two models (full dataset versus nonextrapolated dataset) is relatively minor, varying 0 to $2.5 \%$ over their common range of HAD (80 to

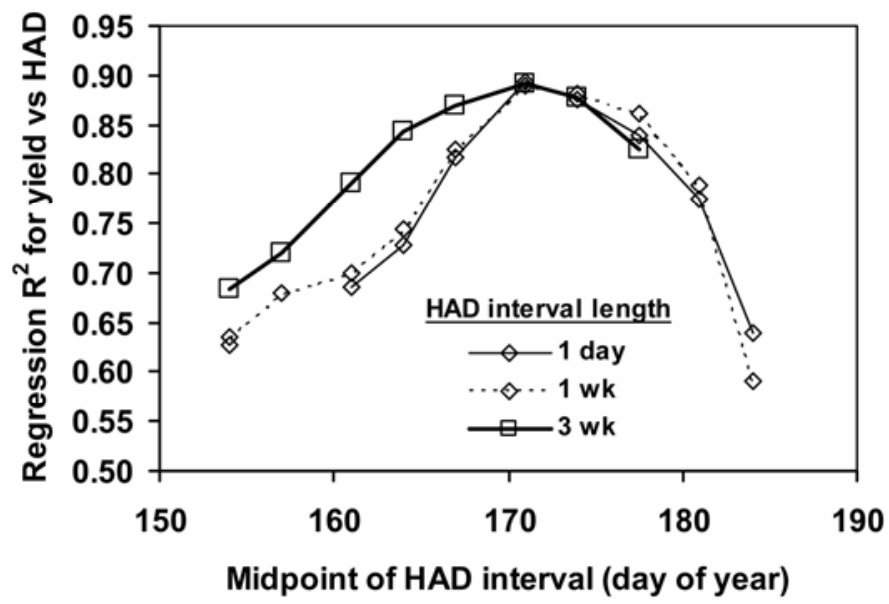

Fig. 2. Predictive value of healthy area duration (HAD) for seed yield of perennial ryegrass affected by stem rust. HAD is the integral of the curve for the nondiseased proportion of the upper canopy over time. Each plotted point is the $r^{2}$ value of the regression analysis for relative yield versus HAD of the indicated interval. The time axis for each experiment was normalized to the average phenological dates for anthesis (day 156) and harvest (day 188). Regression analyses were conducted on data from 66 replicated treatments across 19 experiments and 9 years. 
$100 \%)$. The full data set-fitted equation, which is slightly concave upward and has an adjusted $R^{2}=0.89(64 \mathrm{df})$, is

$$
\text { relative yield }=3.82 x^{2}-3.22 x+0.38
$$

where $x=$ HAD over the 3-week interval centered on day 171 and the domain of HAD is 0.7 to 1.0 .

Yield variability due to factors other than disease is clearly evident in the vertical scatter of points near the coordinates $[1,1]$. It is difficult to distinguish from these data whether there is a portion of the relationship at very low disease severity (high HAD) where disease does not affect yield; however, an examination of data points with HAD values of 0.99 and greater (Fig. 3B) suggests that HADs $>0.99$ of the maximum are associated with little or no damage.

The relationship of yield to HAD can be converted to a damage function (unrealized yield as a function of disease severity) by plotting loss $(1-$ relative yield) versus proportion of diseased area (1 - HAD). The regression equation for this relationship (Fig. $3 \mathrm{C}$ ), with $x=$ proportion of disease, is

$$
\text { loss }=-3.822 x^{2}+4.4324 x+0.0121, \text { adjusted } R^{2}=0.89
$$

If this regression is forced through the origin (i.e., no loss if no disease), it is

$$
\text { loss }=-4.621 x^{2}+4.668 x, \text { adjusted } R^{2}=0.89
$$

This model applies for proportion of disease $\leq 30 \%$; disease $>30 \%$ is assumed to produce losses of $100 \%$.

This damage function (equation 3 ) predicts yield shortfalls of 1 , 5,22 , and $42 \%$ for critical-interval disease proportions of $0.3,1$, 5 , and $10 \%$, respectively. If equation 2 is used, predicted shortfalls are the same as these for disease proportions $>5 \%$ and $\approx 1 \%$ higher for disease proportions $<5 \%$.

Observations of relative yield and HAD from experimental plots not included in the model construction were congruent with model predictions (Fig. 4). These observations were made on various cultivars different from the one used in model construction. Some of these observations were from small plots in 2006 at the same geographic location as the model plots. Others were from large plots on grower farms at various locations in western Oregon in 2005, 2006, in 2007. The correlation coefficient for observed yields versus predicted yields was 0.94 .

\section{DISCUSSION}

We determined that stem rust can cause severe damage, measured as unrealized yield, in perennial ryegrass grown for seed in the northwestern United States. Severity of naturally occurring epidemics varied greatly from year to year over the 9-year study period, such that rust-associated yield shortfalls in nonprotected stands ranged among years from 0 (not significantly different from thoroughly protected stands) to $98 \%$. Economically appropriate fungicides are effective in managing the disease. For these reasons, stem rust in perennial ryegrass seed crops is an appropriate pathosystem for decision support systems to optimize disease management.

Our method for assessing disease severity (and, thus, its complement, proportion of healthy area) was predicated on estimation of functioning photosynthetic area. Given the high LAI of a grass crop grown for seed and its relatively high extinction coefficient (especially when the canopy is lodged), we confined our assessments to the upper 15 to $20 \mathrm{~cm}$ of the canopy, where the majority of light absorption would occur $(3,5,20)$. The magnitude of the healthy proportion of this canopy layer proved to be well correlated with differences in yield among plots with different severi-
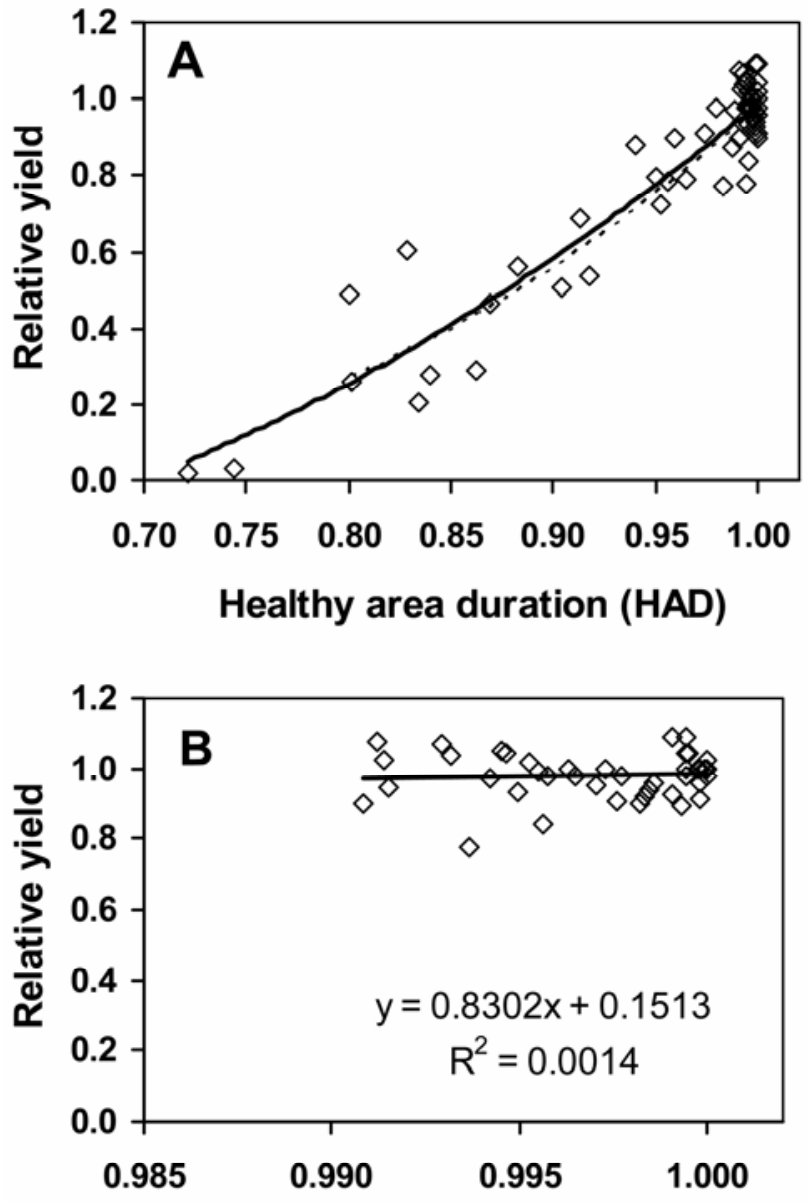

Healthy area duration (HAD)

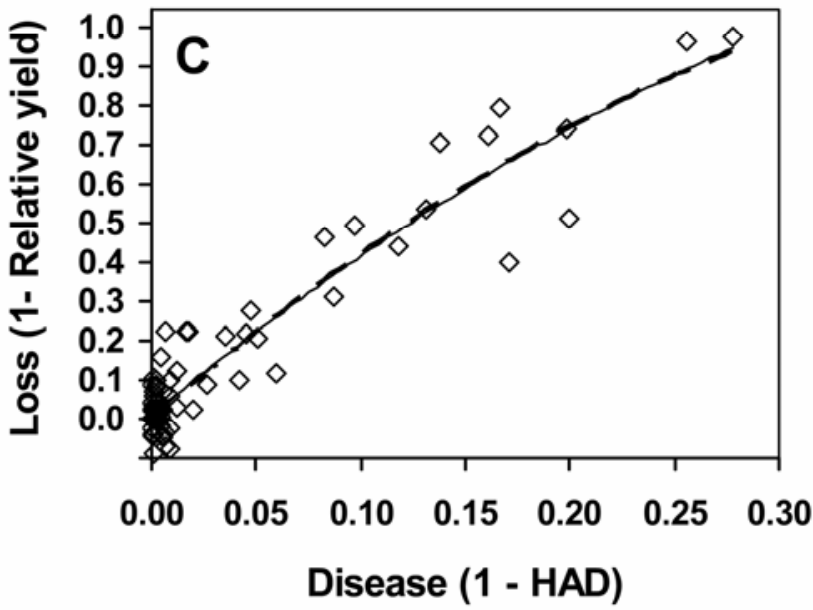

Fig. 3. Relationship of healthy area duration (HAD) to seed yield of perennial ryegrass affected by stem rust. A, Relative yield as a function of the HAD during the 3-week interval centered on the midpoint between anthesis and harvest. Solid line is the regression fit to data from all replicated treatments across all experiments and years, including those experiments for which the reference (nondisease) yield was obtained by extrapolation. Dashed line is the regression fit to the subset of experiments in which the reference treatment was measured directly. Yield is expressed as a proportion of the yield obtained from the nondiseased treatment in each respective experiment. B, Relative yield as a function of $\mathrm{HAD}$ as in $\mathbf{A}$, but only for those treatments with an average disease severity $<1 \%$ during the interval. $\mathbf{C}$, Damage function for stem rust in perennial ryegrass seed crop, created by rearranging the function shown in A; data are as in A. The damage function (thin solid line), is: Loss = $-3.82 x^{2}+4.43 x+0.012$, with $x=1-$ HAD and HAD $>0.7$. If the regression is forced through the origin, the damage function is (heavy broken line): Loss $=-4.62 x^{2}+4.67 x$. The adjusted $r^{2}$ is 0.89 for either function. 
ties of stem rust. This approach is supported by work in other grass pathosystems, such as a detailed study of wheat growth and yield under various severities of leaf rust and Septoria blight, which demonstrated the importance of canopy position in the contribution of healthy area to yield (1). From a practical standpoint, the correlation of upper-canopy healthy area with yield is beneficial, because disease assessment for management decisions does not need to include the lower canopy levels, which are more difficult and time-consuming to assess than is the upper portion of the canopy, especially after lodging.

The HAD for 1 to 3 weeks in the middle of the period between anthesis and 1 week before harvest is clearly indicated as an important phenological stage with respect to damage from stem rust injury. It is not possible to identify a specific point or time window within this period that is particularly critical in the physiological determination of yield, because of the autocorrelation among observation dates with respect to disease severity. Because of the general pattern of epidemic development for stem rust within the season (from low to high severity over time, with some plateaus or minor decreases), stands with a high severity of stem rust 3 weeks after anthesis likely also had a relatively high severity 1 week after anthesis, for example. Given this epidemic pattern, a predictor does not need to be robust across all conceivable disease progress curves that can occur in all pathosystems (for example, severe disease early decreasing to lesser disease as the environment becomes less conducive to the pathogen and more conducive to host growth). The predictor is only required to perform satisfactorily in the pathosystem (in this case, stem rust of grass seed crops) for which it was developed. It is possible that the radiation-intercepting area may be merely a correlate of other, truly causative, physiological components of yield differences (6). For example, water loss is a strong determinant of damage in some pathosystems (6) and could be a factor here because of the extensive epidermal damage caused by stem rust. However, we found no correlation between meteorological measures of evaporative potential and deviations of specific data points from the modeled damage/injury relationship (W. Pfender, unpublished data).

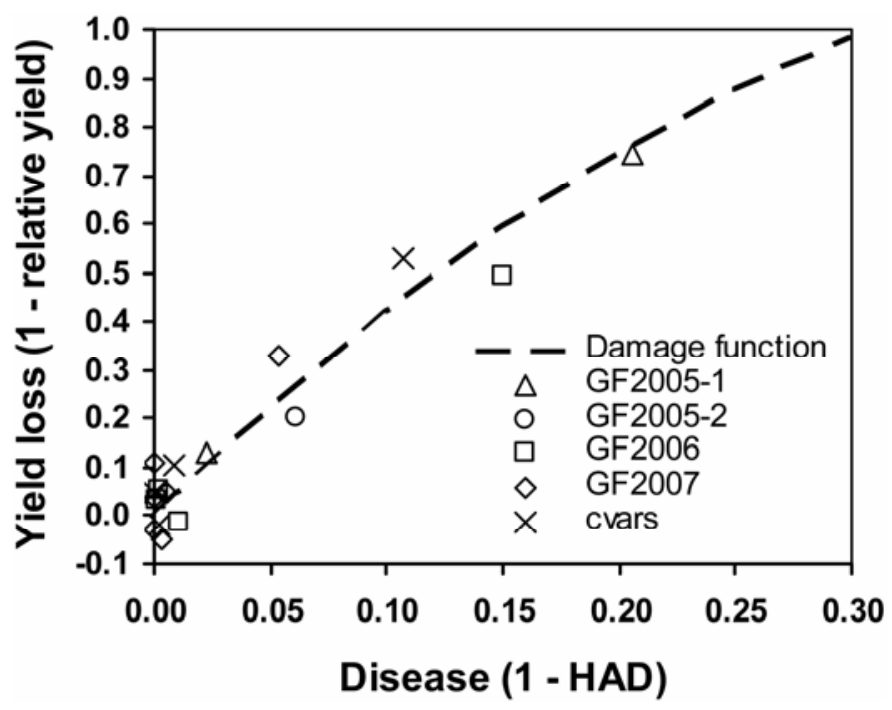

Fig. 4. Damage function plotted on the same axes with data obtained from experiments not used in derivation of the function. The damage function is as shown in Figure 3C. Each point represents the datum from one plot of perennial ryegrass from various experiments, with the yield expressed as proportion of the yield obtained from nondiseased plots in the respective experiment. Some of the plots were large $(5$ by $150 \mathrm{~m})$ in grower fields (GF) in 2005 (two fields), 2006, and 2007. Others (cultivars) were plots of the same size as those used for model development but planted to cultivars not used in model development. The correlation coefficient for observed versus predicted yield was 0.94 .
Our results show that there is a high correlation between yield and the relative amount of nondiseased radiation-intercepting area present at a time midway between anthesis and 1 week before harvest. In our 9-year data set, the single-point predictor (proportion of healthy area on the midpoint day) was as good a predictor as one based on proportion of healthy area integrated over $0.5,1$, or 1.5 weeks before and after this date. We would suggest, however, that one of the longer duration periods may be more robust as a predictor, because the longer time window should smooth out possible variations in severity over the time period.

The function we developed, relating relative yield to proportion of healthy area integrated over a 3-week time window, is a quadratic equation with slight upward curvature (Fig. 3A). It estimates a $22 \%$ yield shortfall correlated with a $5 \%$ reduction in HAD and a $75 \%$ yield shortfall correlated with $20 \%$ reduction in HAD. Using the smaller dataset (Fig. 3A, broken line) derived by omitting experiments for which the nondiseased yield had to be obtained by extrapolation, the respective yield shortfall estimates (25 and $73 \%$ ) are similar to those from the full-data-set model. This similarity indicates that the use of extrapolation for a reference yield in some of the experiments did not introduce serious error into the model. Rust evaluations of grasses and grains typically are expressed on the Cobb scale (18), in which the maximum disease a plant can sustain is $\approx 33 \%$ of its surface area. This maximum value is expressed as $100 \%$ Cobb-scale severity. Thus, our severity values in this article can be converted to Cobb scale severity values by multiplying by 3 .

We constructed the damage function from data collected at the spatial scale of small plots ( 2 by $8 \mathrm{~m}$ ). We did not collect damage/injury information at the individual plant level; such data would be difficult to evaluate because of the highly heterogeneous nature of forage grass cultivars, which have an outcrossing breeding system. Thus, the damage function integrates effects of several processes in addition to physiological damage. For example, spatial aggregation of disease tends to shift the physiological injury/ damage function toward a more linear function (10). Stem rust commonly occurs in foci (i.e., has an aggregated distribution). Therefore, spatial aggregation effects, as well as variability in time of infection for individual plants due to the focus' outward expansion, are integrated in an unknown way into our damage function. Because the dimensions of typical stem rust foci in fields are generally smaller than our plot size (W. Pfender, unpublished data), the plot-level damage function may be a good approximation to a field-level damage function and, thus, applicable to management decision making. In this respect, we note that observations from much larger plots ( 5 by $150 \mathrm{~m}$ ), though limited in number, were generally congruent with model predictions (Fig. 4). The slight curvature of the damage function has the character of a type II damage function (8), which can be associated with effects on radiation use efficiency. However, the magnitude of the curvature is slight and our observations suggest that there is no measurable yield shortfall associated with the first $1 \%$ of reduced HAD (Fig. 3B). Therefore, we suggest that the data are not informative about the presence or absence of radiation use efficiency impairment, particularly given the various spatial and physiological effects that are cryptically included in the observations, as just noted.

In this study, the attainable yield was considered to be represented by the fungicide-protected, disease-free plots. There is some question as to whether this approach may overestimate yield shortfall in diseased plots, because strobilurins may cause a yield stimulation independent of disease control. Observations of "unexpectedly good" yields associated with use of strobilurins in the absence of disease (2) have been reported but have not been rigorously tested due to the difficulty in producing a completely disease-free crop in the field (2). Full reports, with data analysis, for such yield increases are not available. In our data, there are only two field experiments in which the nonsprayed plots had 
insignificant disease $(\leq 1 \%$ severity at harvest) and could be compared with azoxystrobin-treated plots for nondisease effects. In the 2001, mid-planting date experiment (Table 1, experiment $9)$, the yield average for strobilurin-treated plots $(0.0 \%$ final disease) was $8 \%$ greater than the nontreated plots $(0.4 \%$ final disease) but the difference was not statistically significant. This contrasts with one of the 2006 experiments (Table 1, experiment 19), in which the treatment receiving two strobilurin sprays $(0 \%$ final disease) had a $5 \%$ lower yield average than the nonsprayed plots ( $1 \%$ disease); again, the difference was not statistically significant. Given the rare occurrence of disease-free perennial ryegrass stands in the absence of fungicide sprays, we cannot convincingly test for the yield-enhancing effect of strobilurins in this crop. However, our results did not suggest a consistent yield increase due to strobilurin sprays. Therefore, we have not adjusted our damage function for possible bias due to fungicide effects unrelated to disease. Furthermore, use of fungicides against stem rust in perennial ryegrass seed crops is the overwhelmingly common practice in the northwestern United States. Therefore, even if some of the yield increases from fungicide use were due to nondisease effects, the practical outcome relevant to decision makers is the yield differential, whether or not it includes a small component unrelated to disease suppression. An economic analysis of the cost to obtain the differential between the attainable yield and expressed yield would include the cost and cryptic benefit of nonfungicide effects.

The damage function reported here was developed from data for a single cultivar, and additional work may be required to validate or modify it for other cultivars. We note that there is limited evidence (Fig. 4) that the damage function works reasonably well for several other cultivars. We expect the damage function to be useful in decision support systems to optimize economic return on management costs, particularly for the common commercial situations in which stem rust is managed such that HAD for the anthesis-to-harvest period rarely is permitted to fall below 0.9 .

As an outcrossing species with a relatively recent history of domestication and genetic improvement, perennial ryegrass is more similar to natural plant populations than are many of the other graminaceous crops for which damage functions have been developed. Therefore, the results of this study may have relevance also to investigations of disease effects on fitness in natural populations of grasses.

\section{ACKNOWLEDGMENTS}

We thank S. Seguin for excellent technical assistance in this research; and M. Mellbye, G. Gingrich, and T. Silberstein of Oregon State University Extension Service for indispensable assistance in the assessment experiments in grower fields.

\section{LITERATURE CITED}

1. Bancal, M., Robert, C., and Ney, B. 2007. Modelling wheat growth and yield losses from late epidemics of foliar diseases using loss of green leaf area per layer and pre-anthesis reserves. Ann. Bot. 100:777-789.

2. Bartlett, D. W., Clough, J. M., Godwin, J. R., Hall, A. A., Hamer, M., and Parr-Dobrzanski, B. 2002. The strobilurin fungicides. Pest Manag. Sci. 58:649-662.

3. Brougham, R. W. 1958. Interception of light by the foliage of pure and mixed stands of pasture plants. Aust. J. Agric. Res. 9:39-52.

4. Campbell, C. L., and Madden, L. V. 1990. Introduction to Plant Disease Epidemiology. John Wiley and Sons, New York.

5. Faurie, O., Soussana, J. F., and Sinoquet, H. 1996. Radiation interception, partitioning and use in grass-clover mixtures. Ann. Bot. 77:35-45.

6. Gaunt, R. E. 1995. The relationship between plant disease severity and yield. Annu. Rev. Phytopathol. 33:119-144.

7. Hampton, J. G. 1986. Fungicidal effects on stem rust, green leaf area, and seed yield in 'Grasslands Nui' perennial ryegrass. N. Z. J. Exp. Agric. 14:7-12.

8. Johnson, K. B. 1987. Defoliation, disease and growth: A reply. Phytopathology 77:1495-1497.

9. Klein, L. M., and Harmond, J. E. 1971. Seed moisture, a harvest timing index for maximum yields. Trans. Am. Soc. Agric. Eng. 14:121-126.

10. Madden, L. V., and Nutter, F. W. 1995. Modeling crop losses at the field scale. Can. J. Plant Pathol. 17:124-137.

11. Milne, A., Paveley, N., Audsley, E., and Parsons, D. 2007. A model of the effect of fungicides on disease-induced yield loss, for use in wheat disease management decision support systems. Ann. Appl. Biol. 151:113125 .

12. Monteith, J. L. 1977. Climate and the efficiency of crop production in Britain. Philos. Trans. R. Soc. Lond. 281:277-294.

13. Mumford, J. D., and Norton, G. A. 1987. Economics of integrated pest control. Pages 191-200 in: Crop Loss Assessment and Pest Management. P. S. Teng, ed. The American Phytopathological Society, St. Paul, MN.

14. Nutter, F. W., Jr., Teng, P. S., and Royer, M. H. 1993. Terms and concepts for yield, crop loss, and disease thresholds. Plant Dis. 77:211-215.

15. Paveley, N. D., Lockley, K. D., Sylvester-Bradley, R., and Thomas, J. 1997. Determinants of fungicide spray decisions for wheat. Pestic. Sci. 49:379-388.

16. Pfender, W. F. 2004. Effect of autumn planting date and stand age on severity of stem rust in seed crops of perennial ryegrass. Plant Dis. 88:1017-1020.

17. Rabbinge, R. Jorritsma, I. T., and Schans, J. 1985. Damage components of powdery mildew in winter wheat. Neth. J. Plant Pathol. 91:235-247.

18. Roelfs, A. P., Singh, R. P., and Saari, E. E. 1992. Rust Diseases of Wheat: Concepts and Methods of Disease Management. CIMMYT, Mexico, D.F.

19. Savary, S., Teng P. S., Willocquet, L., and Nutter, F. W., Jr. 2006. Quantification and modeling of crop losses: A review of purposes. Annu. Rev. Phytopathol. 44:89-112.

20. Sinoquet, H., Moulia, B., Gastal, F., Bonhomme, R., and Varlet-Grancher, C. 1990. Modeling the radiative balance of the components of a wellmixed canopy: Application to a white clover-tall fescue mixture. Acta Oecol. 11:469-486.

21. Waggoner, P. E., and Berger, R. D. 1987. Defoliation, disease, and growth. Phytopathology 77:393-398.

22. Welty, R. E., and Azevedo, M. D. 1994. Application of propiconazole in management of stem rust in perennial ryegrass grown for seed. Plant Dis. 78:236-240. 